\title{
Opportunities from a new disease for an old threat: Extending COVID-19 efforts to address tuberculosis in South Africa
}

\author{
M Loveday, ${ }^{1,2} \mathrm{PhD} ;$ H Cox, ${ }^{3} \mathrm{PhD} ;$ D Evans, ${ }^{4}$ DTech Biomed; J Furin, ${ }^{5} \mathrm{MD}$, PhD; N Ndjeka, ${ }^{6}$ MMed (Fam Med); \\ M Osman, ${ }^{7} \mathrm{MB}$ ChB, PG Dip Health Management, MSc Epidemiology; K Naidoo, ${ }^{2} \mathrm{MB}$ ChB, PhD; for the National TB \\ Think Tank 'Optimising TB Treatment Outcomes' Task Team*
}

\author{
${ }^{1}$ HIV Prevention Research Unit, South African Medical Research Council, KwaZulu-Natal, South Africa \\ ${ }^{2}$ Centre for the AIDS Programme of Research in South Africa (CAPRISA), Nelson R Mandela School of Medicine, College of Health Sciences, \\ University of KwaZulu-Natal Durban, South Africa; and South African Medical Research Council-CAPRISA HIV-TB Pathogenesis and \\ Treatment Research Unit, Doris Duke Medical Research Institute, University of KwaZulu-Natal Durban, South Africa \\ ${ }^{3}$ Institute for Infectious Disease and Molecular Medicine and Wellcome Centre for Infectious Disease Research in Africa, University of Cape Town, \\ South Africa \\ ${ }^{4}$ Health Economics and Epidemiology Research Office, Department of Internal Medicine, School of Clinical Medicine, Faculty of Health Sciences, \\ University of the Witwatersrand, Johannesburg, South Africa \\ ${ }^{5}$ Department of Global Health and Social Medicine, Harvard Medical School, Boston, USA \\ ${ }^{6}$ Drug-Resistant Tuberculosis, TB and HIV Directorate, National Department of Health, South Africa \\ ${ }^{7}$ Desmond Tutu TB Centre, Department of Paediatrics and Child Health, Faculty of Medicine and Health Sciences, Stellenbosch University, \\ Cape Town, South Africa \\ ${ }^{*}$ Members of the National TB Think Tank 'Optimising TB Treatment Outcomes' Task Team: F Abdullah, N Bantutani, S Charalambous, \\ F Conradie, T Dube, B Kana, M Khan, A Grant, P Hazangwe, M Longwe, R Louw, M Makgabo, R Manesen, K Mekler, L Mvusi, P Pundit, \\ A Swarts, $M$ Uys, E Walters
}

Corresponding author: M Loveday (marian.loveday@mrc.ac.za)

\begin{abstract}
The COVID-19 pandemic and phased nationwide lockdown have impacted negatively on individuals with tuberculosis (TB) and routine TB services. Through a literature review and the perspective of members of a national TB Think Tank task team, we describe the impact of the pandemic and lockdown on TB patients and services as well as the potential long-term setback to TB control in South Africa (SA). Strategies to mitigate risk and impact are explored, together with opportunities to leverage synergies from both diseases to the benefit of the National TB Programme (NTP). With the emergence of COVID-19, activities to address this new pandemic have been prioritised across all sectors. Within the health system, the health workforce and resources have been redirected away from routine services towards the new disease priority. The social determinants of health have deteriorated during the lockdown, potentially increasing progression to $\mathrm{TB}$ disease and impacting negatively on people with TB and their households, resulting in additional barriers to accessing TB care, with early reports of a decline in TB testing rates. Fewer TB diagnoses, less attention to adherence and support during TB treatment, poorer treatment outcomes and consequent increased transmission will increase the TB burden and TB-related mortality. People with TB or a history of TB are likely to be vulnerable to COVID-19. Modifications to current treatment practices are suggested to reduce visits to health facilities and minimise the risks of COVID-19 exposure. The COVID-19 pandemic has the potential to negatively impact on TB control in TB-endemic settings such as SA. However, there are COVID-19-related health systems-strengthening developments that may help the NTP mitigate the impact of the pandemic on TB control. By integrating TB case finding into the advanced screening, testing, tracing and monitoring systems established for COVID-19, TB case finding and linkage to care could increase, with many more TB patients starting treatment. Similarly, integrating knowledge and awareness of TB into the increased healthcare worker and community education on infectious respiratory diseases, behavioural practices around infection prevention and control, and cough etiquette, including destigmatisation of mask use, may contribute to reducing TB transmission. However, these potential gains could be overwhelmed by the impact of increasing poverty and other social determinants of health on the burden of TB.
\end{abstract}

S Afr Med J 2020;110(12):1160-1167. https://doi.org/10.7196/SAMJ.2020.v110i12.15126

In January 2020, SARS-CoV-2, causing COVID-19 disease, was isolated in Wuhan City, China. ${ }^{[1,2]}$ By March 2020, as countries throughout the world reported increasing cases, the World Health Organization (WHO) declared the outbreak a pandemic. ${ }^{[3]}$ At the time of writing (15 September 2020) there were 29279316 confirmed cases from 188 countries and 928403 deaths. ${ }^{[4]}$ In South Africa (SA), the first laboratory-confirmed case of COVID-19 was recorded on 5 March 2020. ${ }^{[5]}$ Despite the SA President declaring a National State of Disaster and a complete lockdown with phased reversal of lockdown conditions, on 15 September 2020 there were 648214 confirmed cases and 15520 reported deaths. ${ }^{[4]}$

In contrast, tuberculosis (TB) is one of the world's oldest diseases, and is known to have affected humanity for at least 70000 years. ${ }^{[6,7]}$ Although preventable and treatable, TB remains one of the top 
10 causes of death worldwide, causing more deaths than HIV/ AIDS. ${ }^{[8]}$ In 2018, an estimated 10 million people developed TB disease, with 1.45 million deaths attributed to TB. ${ }^{[8]}$ In SA, although the annual number of $\mathrm{TB}$ cases reported has decreased over the past decade, 235652 new cases were reported in 2018 and TB remains the leading cause of death, with 28678 TB-related deaths in 2017..$^{[9,10]}$

The substantial effect of the COVID-19 pandemic on TB services globally has been reported. ${ }^{[11]}$ With the disruptions and reorganisation of services in response to the pandemic, delays in TB diagnosis and treatment initiation may result in increased transmission and new cases. Globally a projected setback of 5 - 8 years in TB incidence and deaths is projected for 2021, with TB mortality estimated to increase by $20 \% \cdot{ }^{[12-14]}$ This additional loss of life over 5 years may be of the same magnitude as the direct impact from COVID-19. ${ }^{[12,13]}$

In this article, through a literature review and perspectives of members of a national TB Think Tank task team, we explore the impact and unintended consequences of the COVID-19 pandemic and phased nationwide lockdown on TB patients and the routine TB services in SA. We describe modifications to the management of drug-susceptible (DS)- and rifampicin-resistant (RR)-TB and explore opportunities that a 'new disease' (COVID-19) may offer for an 'old threat' (TB). ${ }^{[7]}$

\section{Methods}

The TB Think Tank was set up to advise the National TB Programme on achieving the TB-related Sustainable Development Goals. Members include individuals from the SA National Department of Health, research institutions, technical support agencies, funders and the WHO. ${ }^{[15]}$ The TB Think Tank developed this article based on observations since the beginning of the COVID-19 pandemic in SA and an initial literature review. The review was conducted using PubMed and Ovid databases between 1 December 2019 and 10 June 2020 using the search terms 'tuberculosis', 'COVID-19' and 'coronavirus'. The literature was summarised, discussed and analysed by a core group at three meetings. The manuscript was circulated to all task team members for input. This article represents a compilation of the available literature and the real-time experiences, perspectives and expertise of the members of the TB Think Tank task team. The objective is to highlight areas where the TB programme could benefit from the strategies introduced to address the COVID-19 pandemic.

\section{The impact of the COVID-19 pandemic and lockdown}

Addressing the challenges of this 'new disease' (COVID-19) has required unprecedented responses with unintended consequences, impacting negatively on the very people these responses intended to protect. In countries hardest hit by COVID-19, socially disadvantaged populations have borne the brunt of the epidemic, with higher numbers affected and higher mortality rates. ${ }^{[16,17]}$

\section{People with TB: A vullnerable group}

Historically, for many socioeconomic reasons, people who develop active TB disease are a vulnerable population. ${ }^{[18]}$ The lockdown has increased poverty and exacerbated other social determinants of health, impacting negatively on people with TB and their households. ${ }^{[19]}$ With movement restricted during the lockdown, people living in informal settlements or overcrowded hostels have spent more time indoors with poor ventilation and increased exposure to indoor air pollution. In such settings, prolonged time spent indoors could accelerate transmission of both TB and COVID19 , as social distancing is not possible, masks are not worn inside homes, and hand hygiene is compromised owing to limited access to water. Furthermore, in people co-infected with TB and COVID19 , increased coughing due to COVID-19 is likely to have increased both COVID-19 and TB transmission within households.

TB patients are economically vulnerable, ${ }^{[20,21]}$ and particularly vulnerable to the 'economic shock' of the lockdown. During the first 3 months of the pandemic and lockdown there was an 18\% decline in employment in SA, with job losses concentrated among the already disadvantaged, which would include people with $\mathrm{TB}^{\left[{ }^{[19]}\right.} \mathrm{RR}-\mathrm{TB}$ patients often lose their source of income at the time of diagnosis, and disability grants specifically for TB become their only source of income. However, owing to the prioritisation of COVID-19-related grants, applications for grants for RR-TB patients were not processed and doctors appointed to clinically assess the eligibility of patients for grants were not available at facilities (Médecins Sans Frontières, South Africa (Khayelitsha Project), personal communication, June 2020, and Bhekisisa Centre for Health Journalism ${ }^{[22]}$ ). During the lockdown the incidence of households running out of money for food doubled. ${ }^{[19]}$ Where income security is threatened, food security is threatened, malnutrition increases, and the risk of TB infection and progression to TB disease increases.

TB patients are at increased risk of depression as a result of fatigue, weight loss, stigma, discrimination, social isolation and rejection. Furthermore, some anti-TB drugs induce depression. ${ }^{[23]}$ The risk of depression may have been exacerbated by the sense of isolation during the lockdown, the stress around accessing treatment, and anxiety about poor treatment outcomes and transmitting TB to household contacts. ${ }^{[24]}$ The economic impact of the lockdown will further increase this psychological stress, contributing to depression.

Owing to pre-existing lung damage, TB patients who become infected with COVID-19 are at increased risk of more serious morbidity and increased mortality ${ }^{[25]}$ For this reason, former TB patients, of whom there are many in SA (10/1 000 population), are also a vulnerable group. ${ }^{[26,27]}$ Recent data from Western Cape Province show that people with active TB were over 2.5 times more likely to die of COVID-19 than people without TB (adjusted hazard ratio (aHR) 2.70; 95\% confidence interval (CI) 1.81 - 4.04), and that people with a previous history of TB had a slightly increased risk of death from COVID-19 (aHR 1.41; 95\% CI 1.18 - 1.93). ${ }^{[25]}$ Given that HIV was also shown to be associated with COVID-19 mortality (aHR 2.14; $95 \%$ CI $1.70-2.70$ ), the vulnerability of TB and former TB patients will be exacerbated in those co-infected with HIV and those with comorbidities such as diabetes mellitus and hypertension. ${ }^{[8,28,29]}$

\section{Access to services}

The difficulty of accessing health services during the COVID-19 pandemic increased for several reasons: (i) movement was restricted, requiring a permit, and this restriction was enforced by the South African Police Service and national army, using roadblocks and patrols; (ii) TB and COVID-19 are both diseases of the respiratory tract, with an overlap of the most common symptoms (cough and fever), so in an environment of anxiety around a new and potentially fatal disease, a person who has developed symptomatic TB would be fearful of COVID-19 and the associated stigma, and delay accessing healthcare; ${ }^{[30]}$ (iii) concern about leaving the house, fear of police intimidation and violence, belief that the new disease may be concentrated in health facilities, and the risk of COVID-19 exposure while travelling to and within a health facility; (iv) less reliable public transport and increased family responsibilities such as caring for children not at school; and $(v)$ those unable to earn an income during the lockdown were unable to afford the transport costs to access a 
health facility. The National Income Dynamics Study - Coronavirus Rapid Mobile Survey (NIDS-CRAM) reports that 23\% of those who needed to access health services during the lockdown were unable to do so. ${ }^{[19]}$

\section{TB services and the TB programme} One of the unintended consequences of the COVID-19 pandemic and phased national lockdown has been the impact on routine health services. ${ }^{[31]}$ Routine health services have been deprioritised; resources have been diverted and the workforce repurposed away from routine services to COVID-19 activities. Many of the gains of the $\mathrm{TB}$ programme over the past decade are being undermined, and it may take years to regain the TB programme's pre-COVID-19 status.

Active case finding, TB diagnosis and prevention services Difficulties in accessing health facilities have led to fewer people accessing health services, which, together with the disruption of routine services, has impacted on TB case finding. ${ }^{[32]}$ From prelockdown to levels 5 and 4 of the lockdown, TB testing and diagnosis decreased by $50 \%$ and $33 \%$, respectively. ${ }^{[32]}$ The delayed diagnosis of $\mathrm{TB}$ and consequent increased infectiousness, together with less access to TB preventive therapy and the deprioritisation of TB contact tracing, will increase transmission. ${ }^{[33]}$ This delay may be exacerbated by the overlap of the more common symptoms of both diseases, which complicates the diagnosis of both conditions.

Difficulties in accessing health facilities and the disruption of routine services also delayed the diagnosis of chronic conditions such as HIV, diabetes mellitus and hypertension, which together with poor retention in care and poor management of these conditions will increase susceptibility to TB and COVID-19. ${ }^{[34,35]}$ Similarly, routine infant immunisation services were disrupted, which could result in an increase in more severe forms of disease such as TB meningitis or disseminated TB. ${ }^{[36,37]}$

Despite the challenges, some individuals attended facilities, but with the focus on COVID-19, they were tested for COVID-19 and not for TB. The recent shift to reduce testing by encouraging individuals with symptoms of COVID-19 without specified risk factors to assume that they are infected with COVID-19 and stay at home may result in further delays in the diagnosis of TB.

\section{Retention in care}

Difficulties in accessing health facilities and the disruption of routine services have also led to suboptimal retention in care for TB patients. ${ }^{[31,38,39]}$ Reduced treatment adherence will decrease the chance of favourable TB treatment outcomes and contribute to the development of drug resistance. In facilities where directly observed therapy (DOT) is still operational, treatment has been further compromised as patients had no access to medicine or the necessary support to enable them to take their medication successfully at home. Although community health workers have historically supported the TB programme, during the pandemic most of these activities were suspended.

At the time of diagnosis, patients with RR-TB are often very ill and are hospitalised for treatment initiation. As TB wards have been reprioritised for the COVID-19 pandemic, these patients may not have been hospitalised or have been discharged early, although community-based support structures are limited, weak, and unable to support patients at home. ${ }^{[39]}$ With less frequent visits to facilities there may be delays in the identification of adverse drug reactions (ADRs) and the development of more severe ADRs, requiring hospitalisation.
As patients co-infected with TB and COVID-19 have been shown to have an increased risk of mortality, post-TB treatment lung damage, morbidity and mortality may also increase. ${ }^{[40]}$ Poor retention in TB care and poor management of comorbidities will exacerbate the chances of unfavourable TB treatment outcomes and poor longterm outcomes. ${ }^{[35]}$ For diabetic patients, decreased availability of antihyperglycaemic agents and/or insulin will impact negatively on diabetic control; suboptimal blood glucose control could increase susceptibility to TB and COVID-19. ${ }^{[35]}$ This will be exacerbated by the changes in lifestyle imposed by the lockdown, especially if these persist beyond the lockdown.

\section{Possible solutions}

It is apparent that the COVID-19 pandemic has far-reaching consequences for the burden of TB in SA. To minimise the projected setback to TB control in SA, we need to capitalise on the systems developed to address the pandemic, together with ensuring increased support for TB patients and the TB programme. In this section we detail how strategies to address the COVID-19 pandemic in SA could benefit the TB programme. In Table 1 we summarise the impact of the pandemic and lockdown on health services with mitigation suggestions.

\section{Infection prevention and control}

The COVID-19 pandemic has sparked an interest in infectious diseases and created a platform for public engagement on disease monitoring. It has also provided increased awareness of and improved behavioural practices around respiratory infection prevention and control (IPC) and cough etiquette. Wearing of masks has been normalised, and we believe that this will encourage their use going forward for both patients and healthcare workers. By linking TB with COVID-19 (as they are both respiratory diseases), we have a unique opportunity to support IPC activities that may limit the transmission of TB in the future. Improved IPC at health facilities will reduce the number of healthcare workers who become infected with TB annually.

\section{Screening and testing}

In our TB-endemic setting, given the overlap of clinical signs and symptoms for TB and COVID-19, those who screen positive for either TB or COVID-19 should be tested for both pathogens, ${ }^{[41]}$ creating an efficient mechanism for patients to enter the TB diagnostic pathway. The extensive community-based screening networks deployed for COVID-19 could also support TB screening and linkage to care. Integrated TB and COVID-19 screening and testing campaigns could provide an opportunity to find the estimated 65348 missing people with $\mathrm{TB}$ and increase early detection and diagnosis in people with undiagnosed TB disease. Guidelines on how sputum should be safely collected for testing in the context of COVID-19 have been developed. ${ }^{[41]}$ Furthermore, if a person tests positive for TB, all household contacts and others with whom the person has had regular contact, or who are at a high risk of $\mathrm{TB}$, should be screened for both $\mathrm{TB}$ and COVID-19 with the provision of TB prevention according to new national guidelines.

\section{Testing and tracing}

For many years, the TB programme has struggled with timeous treatment initiation in people diagnosed with TB. The set-up of sophisticated laboratory systems and digital platforms to link positive COVID-19 tests to case identification, tracing and outcome evaluation could benefit the TB programme. If $\mathrm{TB}$ was integrated 
Table 1. Interventions to address the impact of the COVID-19 pandemic and lockdown on TB patients and health services

\begin{tabular}{ll}
\hline Area of concern & Impact of pandemic and lockdown \\
\hline All patients & $\begin{array}{l}\text { Anxiety regarding accessing health } \\
\text { facilities }\end{array}$
\end{tabular}

Suggested interventions

facilities

Vulnerable patients - PLHIV, patients with chronic conditions, TB patients and former TB patients
Increased risk of COVID-19

\section{All health facilities must address community fears and} anxieties about accessing health services with dissemination of information on the strategies that have been implemented at all health facilities to protect the vulnerable and minimise the risk of COVID-19 transmission:

- separating those with COVID-19 symptoms from other clinic attendees

- triaging and fast-tracking coughing patients

- establishing fast lanes to minimise sitting in queues and waiting rooms

- ensuring that facility-level IPC procedures are being implemented. ${ }^{[44,45]}$

$\mathrm{NDoH}$ to draw up pamphlets or posters addressing community fears and anxieties about accessing health services and deliver these to provinces. Provincial health departments to distribute these to all districts, who will ensure delivery to all facilities. Facility managers to ensure that posters are put up on the walls of their facilities and pamphlets delivered. In addition, information sessions addressing these concerns could be held each morning where people are congregated.

All health facilities must:

- inform vulnerable patients that they are at increased risk of morbidity and mortality from COVID-19 infection and the importance of adherence to medication for their existing condition

- minimise the time spent in facilities by triaging and fasttracking vulnerable patients

- reduce facility visits by:

- implementing 2-month minimum dispensing for ART and chronic disease medication

- accelerating the referral of patients to external open-air pick-up points where social distancing is implemented

- refer patients with chronic conditions to external pick-up points for their medication

- explore using CHWs to deliver drugs, as has been done in Western Cape Province. ${ }^{[46]}$

$\mathrm{NDoH}$ to draw up guideline documents detailing how facility visits should be minimised. Provincial health departments will have to establish external pick-up points, and health facilities will have to ensure that these function optimally, and that IPC is implemented.

Inform TB and RR-TB patients that they are at increased risk of morbidity and mortality from COVID-19 infection and therefore:

- must adhere to their anti-TB treatment

- must wear a surgical mask while at a health facility

- will be screened for COVID-19 every time they access a health facility.

Inform former $\mathrm{TB}$ patients that they are also a vulnerable group:

- if they have any signs and symptoms of respiratory disease, they should be tested for both TB and COVID-19

- facility visits to be reduced as described above.

District managers must ensure that there are sufficient masks and COVID-19 test kits available. Facility managers must ensure that TB/RR-TB and former TB patients are informed about their increased risk and how to mitigate this. Facility managers must ensure that all patients are wearing masks and are being screened. 
Table 1. (continued) Interventions to address the impact of the COVID-19 pandemic and lockdown on TB patients and health services

\begin{tabular}{|c|c|c|}
\hline Area of concern & Impact of pandemic and lockdown & Suggested interventions \\
\hline Patients with DS-TB & $\begin{array}{l}\text { Treatment modifications to reduce } \\
\text { COVID-19 risk }\end{array}$ & $\begin{array}{l}\text { To minimise health facility visits: } \\
\text { - Pre-COVID-19, once a patient was diagnosed with DS-TB } \\
\text { they had to access a health facility monthly to monitor their } \\
\text { response to treatment and get a month's supply of anti-TB } \\
\text { medication. To minimise the risk of COVID-19, DS-TB } \\
\text { patients who are relatively well should be provided with a } \\
\text { 2-month supply of intensive-phase TB treatment and ART } \\
\text { (for those co-infected with HIV), returning to the facility } \\
\text { for clinical assessment and continuation-phase medication. } \\
\text { - Patients responding well to treatment should be provided } \\
\text { with the full } 4 \text { months of treatment, returning for an exit } \\
\text { interview. }{ }^{[45]} \\
\text { - More detailed clinical guidelines regarding the management } \\
\text { of DS-TB patients during the pandemic are available from } \\
\text { the South African HIV Clinicians Society, }{ }^{[47]} \text { Cox } e t \text { al. }{ }^{[45]} \\
\text { and the National Department of Health. }{ }^{[4]} \\
\text { To support retention in care: } \\
\text { - develop mHealth adherence support groups and establish } \\
\text { clinical helplines } \\
\text { - explore the use of CHWs to deliver drugs, support retention } \\
\text { in care and collect sputum. } \\
\text { The NDoH will need to draw up guideline documents for the } \\
\text { treatment of TB/RR-TB during the pandemic. Provincial health } \\
\text { departments will have to ensure that all districts are informed } \\
\text { of these guideline documents and are implementing them. } \\
\text { Provincial managers will need to ensure that drug stocks are } \\
\text { sufficient, and district and facility managers to ensure that there } \\
\text { are sufficient drugs at each facility. } \\
\text { Financial resources made available by the NDoH should be } \\
\text { used by provincial TB managers to contract NGOs to set up, } \\
\text { monitor and evaluate mHealth adherence support groups and } \\
\text { clinical helplines. Their functioning will need to be monitored } \\
\text { and evaluated by district and facility managers. }\end{array}$ \\
\hline RR-TB patients & $\begin{array}{l}\text { Treatment modifications to reduce } \\
\text { COVID-19 risk }\end{array}$ & $\begin{array}{l}\text { To minimise health facility visits: } \\
\text { - Any patient on an injectable regimen should be urgently } \\
\text { transitioned to an oral regimen }{ }^{[48]} \\
\text { - Patients' clinical assessments and treatment refills should } \\
\text { be aligned at } 2,4 \text { and } 8 \text { weeks, and for those who culture } \\
\text { convert, thereafter every } 2 \text { months. } \\
\text { - Given the serious implications of a rapid drop in } \\
\text { haemoglobin levels for patients on linezolid, and of a } \\
\text { prolonged QT interval in patients on bedaquiline, initial } \\
\text { biweekly monitoring of blood levels and cardiac activity must } \\
\text { not be minimised. } \\
\text { - More detailed clinical guidelines are available. }{ }^{[45,47,48]} \\
\text { To support retention in care: } \\
\text { - develop mHealth adherence support groups and establish } \\
\text { clinical helplines } \\
\text { - establish clinical helplines and telephonic follow-up of blood } \\
\text { results and dose adjustment by clinicians where feasible } \\
\text { - explore the use of CHWs to deliver drugs, support retention } \\
\text { in care and collect sputum. } \\
\text { The details for implementation are described in the section on } \\
\text { DS-TB patients above. }\end{array}$ \\
\hline
\end{tabular}


Table 1. (continued) Interventions to address the impact of the COVID-19 pandemic and lockdown on TB patients and health services

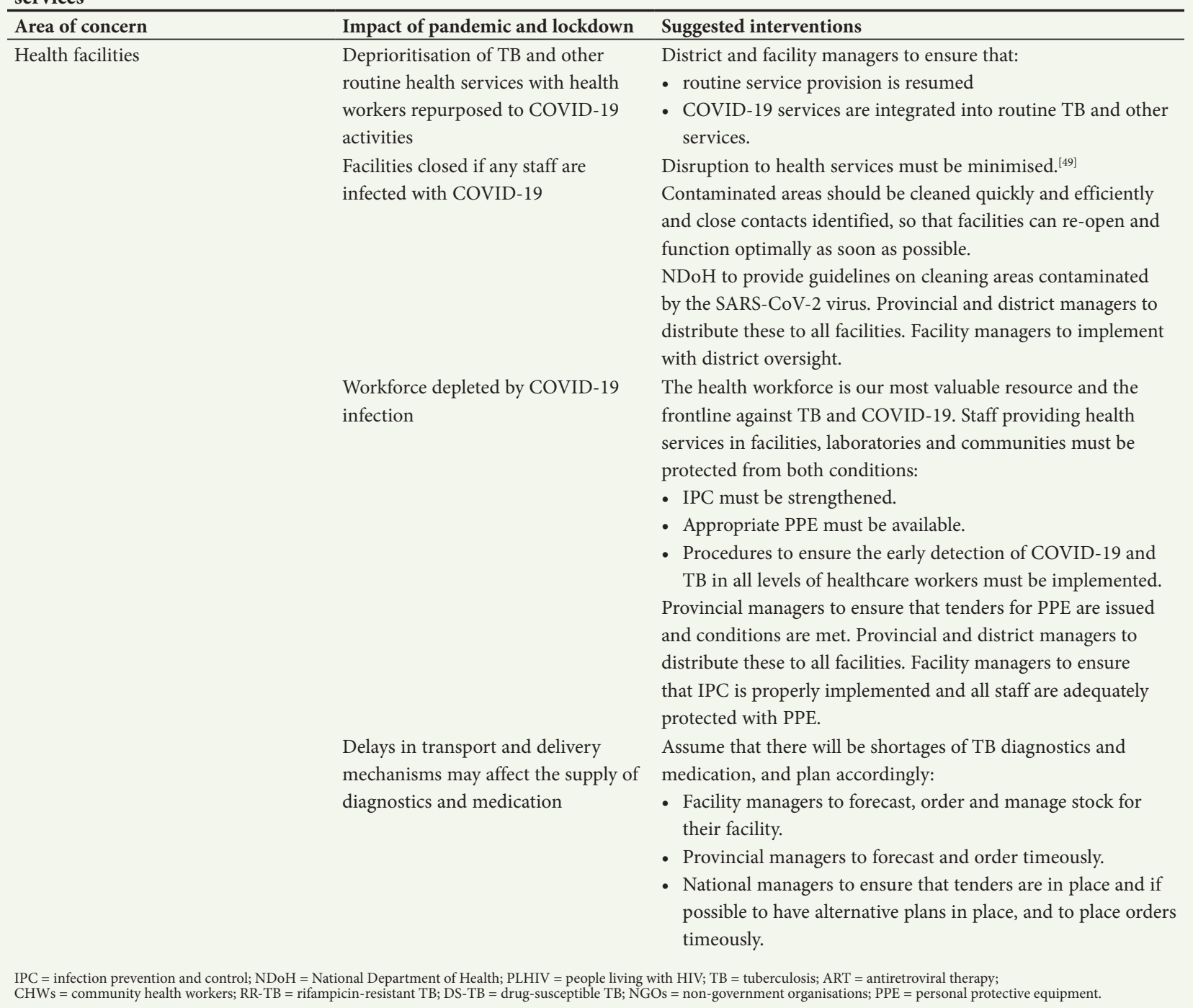

into the geospatial mapping system set up to inform the COVID-19 tracing efforts and tracking in real time, this could strengthen the tracing of contacts, recording and notification processes of both the TB and RR-TB programmes. ${ }^{[42]}$ Previously, there has been a reluctance to notify patients through short message service (SMS) (text message) systems of their TB results, owing to fears of inadvertent disclosure and increased stigma. With COVID-19, the notification of negative results through SMS allowed for quick delivery of results and reduced the need for follow-up of results by patients. The delivery of negative TB results is currently being explored by the National Institute for Communicable Diseases.

\section{TB treatment services}

COVID-19 has forced 'at-home' management of patients with mild to moderate respiratory symptoms, with links to health services via toll-free helplines, links to practitioners using virtual systems, and the creation of virtual WhatsApp support groups. The creation of these systems provides a long-overdue opportunity to replace TB DOT with virtual supportive adherence counselling and clinical management, and could supplement the existing digital and mobile health technologies (mHealth solutions). Use of these systems would minimise facility visits, limit nosocomial TB transmission, and protect TB patients from emerging infectious diseases. Individuals who do not attend their routine appointments to pick up their medication need to be contacted telephonically and counselled on the importance of adherence.

Addressing the social determinants of health is key to TB control. ${ }^{[43]}$ Given the increased vulnerability of TB patients during the COVID-19 pandemic and lockdown, the resources mobilised during the pandemic to reduce poverty and provide nutritional and economic support must continue, prioritising those most at risk of the disease and severe forms of the disease. Mechanisms to deliver this aid have been established through the COVID-19 response by engagement with communitybased organisations that could be explored for the continued delivery of support for people with TB.

\section{Monitoring and evaluation}

The COVID-19 pandemic has introduced public health reporting, with the SA President and Minister of Health addressing the country frequently to inform an understanding of the disease, its key indicators and the strategies adopted. The term 'flatten the curve' has been introduced, and the general public has been educated and empowered to understand and engage with the COVID-19 data (Fig. 1). Resources have been made available (https://sacoronavirus. co.za/) and hotlines established. 


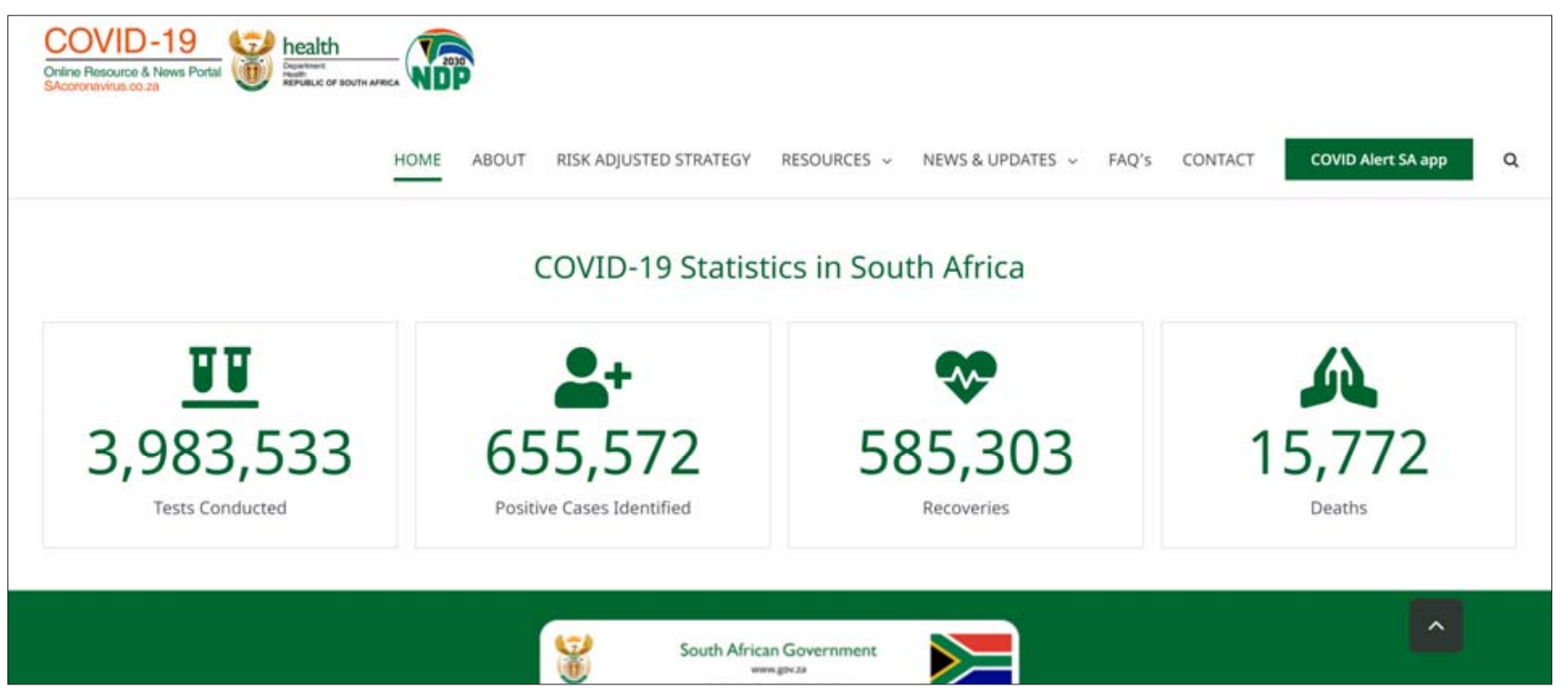

Fig. 1. Screenshot of the COVID-19 statistics updated daily on the South African National Department of Health coronavirus website (https://sacoronavirus.co.za/), accessed 18 September 2020.

Limited resource allocation and subsequent suboptimal monitoring and evaluation have plagued the TB programme for years. Despite the country burden of TB, real-time data of TB test positivity, linkage to care, hospitalisation and treatment outcomes are not available. We now have an opportunity for the TB programme to leverage public interest in infectious diseases and data, and lobby for improved reporting and surveillance systems for $\mathrm{TB}$, improved integration of health information systems and improved mortality reporting. Going forward, the reporting systems set up for COVID-19 should be expanded to include TB and generate public engagement with the burden of TB and its control in SA.

\section{Funding for infectious diseases}

Given the effect of the COVID-19 pandemic on global and local economies as well as the everyday lives of individuals, awareness of infectious diseases on the part of populations and governments will increase, leading to increased prominence of the control of infectious diseases such as TB. This interest should be leveraged to increase investment from governments for TB.

\section{Future research}

To establish the prevalence of TB among COVID-19 patients, specimens obtained from people diagnosed with COVID-19 could be tested for TB. In our setting, a more detailed analysis of the risk of severe COVID-19 to people with TB, RR-TB or previous TB is required. Careful documentation and analysis of simultaneous treatment and treatment outcomes will inform clinical management of co-infected patients. Finally, it is not known whether people who were infected with SARS-CoV-2 are at increased risk of TB post COVID-19 disease, or whether COVID-19 infection in those with current or previous TB puts them at increased risk of developing long-term respiratory complications.

\section{Conclusions}

As we struggle to deal with the COVID-19 pandemic, every effort must be made to ensure that its impact does not create a second tragedy for the vulnerable $\mathrm{TB}$ community. To preserve the gains made over the past decade in the fight against $\mathrm{TB}$ and mitigate the consequences of COVID-19 on TB, prioritised funding and mobilisation of resources will be required to strengthen $\mathrm{TB}$ control strategies and prioritise the delivery of TB and HIV diagnostic and treatment services. Although the COVID-19 pandemic is expected to continue to 2021, TB will be around for many years to come. However, if we build on the opportunities presented by the pandemic we could, in the long run, reduce $\mathrm{TB}$ transmission and the SA TB burden.

\section{Declaration. None.}

Acknowledgements. None.

Author contributions. Conceived and designed the article: National TB Think Tank 'Optimising TB Treatment Outcomes' Task Team. Collection, analysis and interpretation of data: ML, HC, DE, JF, NN, MO, KN. Wrote the paper: ML, HC, DE, JF, NN, MO, KN. All authors had full access to all the data in the study. ML as corresponding author had final responsibility for the decision to submit for publication. The final version of the manuscript has been read and approved by all the authors.

Funding. The TB Think Tank is supported by the Bill and Melinda Gates Foundation. ML is supported by the South African Medical Research Council. The funder had no role in study design, the collection, analysis and interpretation of data, the writing of the report, or the decision to submit the article for publication. All researchers were independent of funders and sponsors.

Conflicts of interest. None.

1. Gorbalenya AE, Baker SC, Baric RS, et al. Severe acute respiratory syndrome-related coronavirus: The species and its viruses - a statement of the Coronavirus Study Group. bioRxiv 2020 (epub 11 February 2020). https://doi.org/10.1101/2020.02.07.937862

2. Phelan AL, Katz R, Gostin LO. The novel coronavirus originating in Wuhan, China: Challenges fo global health governance. JAMA 2020;323(8):709-710. https://doi.org/10.1001/jama.2020.1097

3. World Health Organization. WHO announces COVID-19 outbreak a pandemic. 12 March 2020 https://www.euro.who.int/en/health-topics/health-emergencies/coronavirus-covid-19/news/ https://www.euro.who.int/en/health-topics/health-emergencies/coronavirus-cov/d-1

4. World Health Organization. Coronavirus disease (COVID-19) pandemic. 2020. https://www.who.int/ World Health Organization. Coronavirus disease (COVID-19) panden
emergencies/diseases/novel-coronavirus-2019 (accessed 6 July 2020).

5. Centre for Systems Science and Engineering (CSSE) at Johns Hopkins University (JHU) COVID-19 dashboard. 2020. https://gisanddata.maps.arcgis.com/apps/opsdashboard/index.html\#/ bda7594740fd40299423467b48e9ecf6 (accessed 19 September 2020).

6. Grange J. The global burden of tuberculosis In: Porter J, Grange J, eds. Tuberculosis: An Interdisciplinary Perpective. London: Imperial College Press, 1999:3-31.

Dara M, Sotgiu G, Reichler M, et al. New diseases and old threats: Lessons from tuberculosis for the COVID-19 response. Int J Tuberc Lung Dis 2020;24(5):544-545. https://doi.org/10.5588/ijtld.20.0151 8. World Health Organization. Global Tuberculosis Report 2019. 17 October 2019. https://www.who.int/ tb/publications/global_report/en/ (accessed 19 September 2020).

9. Massyn N, Barron P, Day C, et al. District Health Barometer 2018/2019. Durban: Health Systems Trust, 2020. https://www.hst.org.za/publications/District\%20Health\%20Barometers/ District+Health+Barometer+2018-19+Web.pdf (accessed 19 September 2020). 
10. Statistics South Africa. Mortality and causes of death in South Africa: Findings from death notification 2017. Pretoria: Stats SA, 2020. http://www.statssa.gov.za/publications/P03093/P030932017.pdf (accessed 19 September 2020).

11. Migliori GB, Thong PM, Akkerman O, et al. Worldwide effects of coronavirus disease pandemic on tuberculosis services, January - April 2020. Emerg Infect Dis 2020;26(11). https://doi.org/10.3201/ eid2611.203163

12. Stop TB Partnership. The potential impact of the Covid-19 response on tuberculosis in high-burden countries: A modelling analysis. May 2020. http://www.stoptb.org/assets/documents/news/Modeling\%20 Report_1\%20May\%202020_FINAL.pdf (accessed 19 September 2020).

13. Hogan A, Jewell B, Sherrard-Smith E, et al. The potential impact of the COVID-19 epidemic on HIV, TB and malaria in low- and middle-income countries. Imperial College London, 1 May 2020. https:// doi.org/10.25561/78670

14. Cilloni L, Fu H, Vesga J, et al. The potential impact of the COVID-19 pandemic on the tuberculosis epidemic - a modelling analysis. medRxiv 2020 (epub 20 May 2020). https./doi. org/10.1101/2020.05.16.20104075

15. White RG, Charalambous S, Cardenas V, et al. Evidence-informed policy making at country level Lessons learned from the South African Tuberculosis Think Tank. Int J Tuberc Lung Dis 2018;22(6):606Lessons learned from the South African

16. Mein SA. COVID-19 and health disparities: The reality of 'the Great Equalizer'. J Gen Intern Med 2020;35(8):2439-2440. https://doi.org/10.1007/s1 1606-020-05880-5

7. Liu Y, Bi L, Chen Y, et al. Active or latent tuberculosis increases susceptibility to COVID-19 and disease severity. medRxiv 2020 (epub 16 March 2020). https://doi.org/10.1101/2020.03.10.20033795

18. Grange J, Story A, Zumla A. Tuberculosis in disadvantaged groups. Curr Opin Pulm Med 2001;7(3):160164. https://doi.org/10.1097/00063198-200105000-00008

19. Spaull N, Ardington C, Bassier I, et al. NIDS-CRAM Synthesis Report Wave 1: Overview and findings. September 2020. http://resep.sun.ac.za/nids-cram-wave-1-synthesis-report-overview-and-findings/ (accessed 19 September 2020).

20. Lönnroth K, Jaramillo E, Williams BG, Dye C, Raviglione M. Drivers of tuberculosis epidemics: The role of risk factors and social determinants. Soc Sci Med 2009;68(12):2240-2246. https://doi.org/10.1016/j. of risk factors and soci
socscimed.2009.03.041

21. Foster N, Vassall A, Cleary S, et al. The economic burden of TB diagnosis and treatment in South Africa Soc Sci Med 2015;130(April):42-50. https://doi.org/10.1016/.jsocscimed.2015.01.046

22. Bhekisisa Centre for Health Journalism. SASSA vs COVID: We don't have a chance. 2020. https://ehwoza. com/sassa-vs-covid (accessed 27 September 2020).

23. Koyanagi A, Vancampfort D, Carvalho AF, et al. Depression comorbid with tuberculosis and its impact on health status: Cross-sectional analysis of community-based data from 48 low- and middle-incom countries. BMC Med 2017;15(1):209. https://doi.org/10.1186/s12916-017-0975-5

24. Rajkumar R. COVID-19 and mental health: A review of the existing literature Asian J Psychiatr 2020;52:102066. https://doi.org/10.1016/j.ajp.2020.102066

25. Boulle A, Davies M-A, Hussey H, et al. Risk factors for COVID-19 death in a population cohort study from the Western Cape Province, South Africa. Clin Infect Dis 2020;ciaa1 198. https://doi.org/10.1093/ $\mathrm{cid} / \mathrm{ciaal} 198$

26. Marx FM, Floyd S, Ayles $\mathrm{H}$, et al. High burden of prevalent tuberculosis among previously treated people in southern Africa suggests potential for targeted control interventions. Eur Respir J 2016;48(4):1227 in southern Africa suggests potential for targeted co

27. Osman M, Welte A, Dunbar R, et al. Morbidity and mortality up to 5 years post tuberculosis treatment in 28. Avert. Global information and education on HIV and AIDS. 2020. https://www.avert.org/coronavirus/
South Africa: A pilot study. Int Infect Dis 2019:85(Aug):57-63. https://doi.org/10.1016/.iji.2019.05.024 28. Avert. Global information and educa
covid19-HIV (accessed 1 July 2020).

covid19-HIV (accessed 1 July 2020).
9. Berry K, Rodriguez C, Berhanu R, et al. Treatment outcomes among children, adolescents, and adults on treatment for tuberculosis in two metropolitan municipalities in Gauteng Province, South Africa. BMC Public Health 2019;19:973. https://doi.org/10.1186/s12889-019-7257-4

30. Togun T, Kampmann B, Stoker NG, Lipman M. Anticipating the impact of the COVID-19 pandemic on TB patients and TB control programmes. Ann Clin Microbiol Antimicrob 2020;19(1):21. https://dol. org/10.1186/s12941-020-00363-1
31. Liu Q, Lu P, Shen Y, et al. Collateral impact of the Covid-19 pandemic on tuberculosis control in Jiangsu Province, China. Clin Infect Dis 2020;ciaa1289. https://doi.org/10.1093/cid/ciaa1289

32. Madhi SA, Gray GE, Ismail N, et al. COVID-19 lockdowns in low- and middle-income countries: Success against COVID-19 at the price of greater costs. S Afr Med J 2020;110(8):724-726. https://doi. org/10.7196/SAMJ.2020.v110i8.15055

33. Getnet F, Demissie M, Worku A, et al. Delay in diagnosis of pulmonary tuberculosis increases the risk of pulmonary cavitation in pastoralist setting of Ethiopia. BMC Pulm Med 2019;19(1):201. https://doi.org/10.1186/s12890-019-0971-y

34. Dooley K, Chaisson R. Tuberculosis and diabetes mellitus: Convergence of two epidemics. Lancet Infect Dis 2009;9(12):737-746. https://doi.org/10.1016/S1473-3099(09)70282-8

35. Pal R, Bhadada SK. COVID-19 and diabetes mellitus: An unholy interaction of two pandemics. Diabetes Metab Syndr 2020;14(4):513-517. https://doi.org/10.1016/j.dsx.2020.04.049

36. Baleta A. Covid-19 side-effect: Dramatic drop in SA's immunisation rates. Daily Maverick, 24 June 2020. https://www.dailymaverick.co.za/article/2020-06-24-covid-19-side-effect-dramatic-drop-insas-immunisation-rates/\#gsc.tab $=0$ (accessed 1 July 2020).

37. Dookie N, Padayatchi N, Naidoo K. Tuberculosis elimination in the era of COVID-19: A moving target. Clin Infect Dis 2020;ciaa1400. https://doi.org/10.1093/cid/ciaal400

38. Karrim A, Evans S. Unscientific and nonsensical: Top scientist slams government's lockdown strategy. Karrim A, Evans S. Unscientific and nonsensical: Top scientist slams governments lockdown strategy.
News24, 16 May 2020 https://wwwnews24com/news24/SouthAfrica/News/unscientific-and-nonsensicaltop-scientific-adviser-slams-governments-lockdown-strategy-20200516 (accessed 26 May 2020).

39. Cleary K. Covid-19: Lockdown takes heavy toll on SA's TB response. City Press, 21 May 2020. https:// . Cleary K. Covid-19: Lockdown takes heavy toll on SA's TB response. City Press, 21 May 2020. https://
city-press.news24.com/News/covid-19-lockdown-takes-heavy-toll-on-sas-tb-response-20200520 (accessed 5 June 2020).

40. Bhekisisa Centre for Health Journalism. Why TB and HIV deaths may increase during COVID-19. 9 June 2020. https://bhekisisa.org/multimedia/2020-06-09-standing-by-when-epidemics-collidedoes-hiv-tb-cause-worse-covid-19/ (accessed 27 September 2020).

41. Conradie F. Treatment of TB and COVID. National Department of Health, South Africa, March 2020.

42. Medical Brief. Mapping technology to help stop COVID-19 in its tracks in SA, one hotspot at a time. 13 May 2020. https://www.medicalbrief.co.za/archives/mapping-technology-to-help-stop-covid-19in-its-tracks-in-sa-one-hotspot-at-a-time/ (accessed 15 June 2020).

43. Rasanathan K, Sivasankara Kurup A, Jaramillo E, Lönnroth K. The social determinants of health: Key to global tuberculosis control. Int J Tuberc Lung Dis 2011;15(Suppl 2):30-36. https://doi. org/10.5588/ijtld.10.0691

44. National Department of Health, South Africa. Response to reduce risk among HIV and TB patients within the context of the COVID-19 pandemic: The South African response to COVID-19. May 2020. http://www.differentiatedcare.org/Portals/0/adam/Content/fvQNZe6lGUOXzejUivJIHA/File/ COVID_HIV_TB_Response_v8_Final_17Apr20.pdf (accessed 1 July 2020).

45. Cox V, Wilkinson L, Grimsrud A, et al. Critical changes to services for TB patients during the COVID-19 pandemic. Int J Tuberc Lung Dis 2020;24(5):542-544. https://doi.org/10.5588/ ijtld.20.0205

46. Brey Z, Mash R, Goliath C, Roman D. Home delivery of medication during coronavirus disease 2019, Cape Town, South Africa: Short report. Afr J Prim Health Care Fam Med 2020;12(1):e1-e4. https://doi.org/10.4102/phcfm.v12i1.2449

47. South African HIV Clinicians Society. Position statement of SAHCS on service delivery to TB patients (drug-susceptible and drug-resistant) during the COVID-19 pandemic. 28 March 2020. https://sahivsoc.org/Files/SAHCS\%20position\%20statement\%2028032020.pdf (accessed 15 June 2020).

48. National Department of Health, South Africa. Managment of DR-TB patients on treatment during the COVID-19 outbreak. April 2020

49. eNCA. COVID-19: KZN healthcare centre closed after six nurses test positive. 16 May 2020. https://www. enca.com/news/kzn-health-care-centre-closed-after-six-nurses-test-positive (accessed 30 June 2020).

Accepted 9 October 2020. 